\title{
Understanding Micrographs: An Educational Activity
}

\author{
Craig Johnson \\ Central Washington University
}

\begin{abstract}
\end{abstract}
It is commonly accepted that there are various teaching and learning styles, and that different combinations are more effective depending on the participants and environment. Moreover, learning which involves more than listening, such as teamwork and labwork, will benefit comprehension and retention. Most materials textbooks do not have an abundance of these educational activities.

This paper introduces a cooperative learning activity supporting the topic of micrographs and microstructural characterization. It takes at least half an hour, and is flexible in scope of content. It starts with a short introduction on outcomes, and then has the students discuss terminology with their neighbors. After another short discussion, the students pair off and follow a procedure for verbally describing a known microstructure, and having their partner listen and recreate it. To conclude the activity, the class has a discussion of the student's experiences. A critical thinking question is provided as an assessment tool.

Introduction

Enhancing communication and teamwork skills is an outcome stated in the Accreditation Board of Engineering and Technology ${ }^{1}$, and is approached in different ways. The Mechanical Engineering Technology (MET) Program at Central Washington University (CWU) has a number of course requirements addressing technical writing, presentations and speaking. However, unlike Seat and Lord ${ }^{2}$, we have no course requirement dedicated to group skills and further integration at a program level. In CWU's MET program almost all of the courses have some in-situ laboratory work, and therefore an opportunity to build teamwork skills on an activity level.

\section{Class Activities}

For a number of years we have known of different teaching and learning styles, in many ways best defined by personal traits (e.g. Myers-Briggs Type Indicator ${ }^{3}$ ). Felder incorporated different educational methods into his chemistry courses at North Carolina State University, and eventually took his message in a workshop forum to new faculty across the country. A workshop at Washington State University ${ }^{4}$ referenced articles on topics such as student diversity ${ }^{5}$ and generating creativity ${ }^{6}$. But applying the concepts to a particular field, program and course requires a methodology that was not addressed.

In an informal survey of MET textbooks, it was found that they are not structured for intra-group learning. Two other resources proved useful is generating discrete course activities. The Center 
for Critical Thinking ${ }^{7}$ offers workshops, seminars and literature that include methods for "redesigning a segment of your teaching". Critical Thinking provides a guide that can be used to both develop and gage the success of the activity.

The second resource is Pacific Crest and their efforts to design and promote Process Education. Under the leadership of Dan Apple the company has published literature ${ }^{8}$ and provided workshops to apply Process Education to particular institution needs. In their text, Foundations of Learning ${ }^{9}$, activity design is detailed. The design phase includes references to critical thinking and communication/group skills. This information was used to generate the activity described in this paper.

\section{Understanding Micrographs}

In the last review of our Introduction to Metallurgy course it was noted that there was inadequate coverage of basic metallographic techniques in the text. In fact, there were a number of poor micrographs in the text, which needed to be enhanced. A way was needed to strengthen the knowledge and experience base of the students so that they could be more critical of the information they were exposed to. A course period was devoted to this outcome, and an activity was designed and shown in Appendix A.

The activity sheet is a single page written on both sides. There is an area at the bottom of the first page for students to list attributes and features, as well as to draw microstructures in. The back side has room for both student attempts at definitions, as well as definitions from the literature. There is a separate sheet for the instructor that lists the literature definitions (see Appendix B).

The activity is designed such that the class participates in a variety of ways. First, the instructor can

1.) First the instructor can review the objective, outcome, deliverables and success.

2.) Then, following the numbered items, the class can work on the 'Spatial Terms' on the back page. Options for this section include working alone or with neighbors (e.g. group work). After a predetermined time, the class can compare their definitions with the literature. A Socratic discussion can ensue. Current events and be incorporated into the discussion (e.g. digital resolution in HDTV, etc.).

3.) The instructor can then show a list of features and attributes on an overhead, and have the students make an attempt at sketching the microstructure (e.g. individual work). This is a timed event after which their sketch is compared with the microstructure the instructor shows on the overhead.

4.) The instructor can use the second sketch area in a number of ways. One way is to have the students pair off and take turns: one student describes a micrograph and the other student sketches it (from an example in the text) and visa versa (e.g. intra-group work). This may take longer than the previous sections, but can be the most productive.

5.) After everyone has had a chance to describe and sketch a micrograph, lead a discussion to reveal any interesting discoveries that were made. 
6.) The last item for the activity is open-ended (and can be assigned as homework). The outcome of the activity refers to the student being able to critique a micrograph. The critical thinking question has the students find both a better and a worse micrograph, explain why, and offer corrections for the deficient micrograph.

The time devoted to this activity can vary. It is possible to hand out the sheet a period early and have the students work on the definitions at home, and then get right into discussing the terms at the beginning of the next class. The discussion of terms is important in that digital imagery has been a boon with regards to cleanliness, but is quite subtle regarding magnification and resolution. It is possible to cut out the second sketch, but it has been noted that there is high time-on-task during this portion of the activity, and it's fun.

\section{Conclusion}

A metallurgy course activity was developed to support both topical and communication outcomes. This activity is easily incorporated into an existing course and mechanical engineering technology program structure. It also uses a variety of class participation techniques including class discussion, group work and cooperative, intra-group learning.

\section{Bibliography}

1. Accreditation Board of Engineering and Technology, http://www.abet.org/tac/9899TACr.html, 1998.

2. Seat and Lord, "Enabling Effective Engineering Teams", J. Eng. Educ., Vol.88, No.4, 1999.

3. Kroeger and Thuesen, "Type Talk", Delta Books, 1998.

4. Felder, "Effective Teaching: A Workshop", at WSU, Publ. By NCSU, 1993.

5. Felder, "Meet Your Students", Chem. Eng. Educ., Spring 1989.

6. Felder, "On Creating Creative Engineers", Engineering Education, January 1967.

7. Paul, "Critical Thinking: Basic Theory", at Seattle, www.sonoma.edu/cthink, 1997.

8. Duncan-Hewitt, Mount and Apple, "A Handbook on Cooperative Learning", Pacific Crest Software, 1995.

9. Krumsieg and Baehr, "Foundations of Learning," Pacific Crest Software, 1996.

\section{CRAIG JOHNSON}

Craig Johnson is an assistant professor in the MET Program of the Industrial and Engineering Technology Department at Central Washington University (www.cwu.edu/ cjohnson). He has an education B.S. in Physical Science and has taught in secondary education, as well as a BSME from U. of Wyoming, an MSMSE from UCLA, and a Ph.D. in Engineering Science from Washington State University specializing in superplasticity and process optimization. 
Appendix A - Understanding Micrographs $\quad$ NAME:

Objective: To understand the attributes and interpretation of optical micrographs and how these correlate with microstructural features.

Outcome: To show your understanding of micrographs by reproducing example microstructures deduced by verbal communication alone, and by critiquing published micrographs.

Activity: 1. Attempt to define the "Spatial Terms" (on the back: $5 \mathrm{~min}$ ). Class discussion after.

2. Refer to the list of features \& attributes (on overhead) and sketch a micrograph.

3. When finished, compare your sketch with the micrograph (on overhead).

4. Pair off. Each take a turn looking at a micrograph, listing attributes and features, and having your partner sketch from your verbal description (use measure bars!).

5. Prepare to discuss your difficulties and successes with the rest of us.

Deliverable: Complete spatial term definitions (on back) and two sketches (below), and critique.

Success: Gage success by comparing your sketch with the micrograph, or use Olympic scoring:

Technical Points (Attributes 1-10) and Artistic Points (1-10 as judged by your peers).

Resources: 1.This handout. 2.Your textbook 3.ASM Ed.9 Hdbk V8 4.Vander Voort,.

\begin{tabular}{|c|c|c|}
\hline List of attributes: & List of features: & Sketch of image: \\
\hline $\begin{array}{l}\text { Micrograph \#1 } \\
\text { (from overhead) }\end{array}$ & & Sketch \\
\hline $\begin{array}{l}\text { Micrograph \#2 } \\
\text { (from partner) }\end{array}$ & & Sketch \\
\hline
\end{tabular}




\section{Appendix A (continued) - SPATIAL TERMS (Attributes):}

1. CONTRAST: (your definition)

(literature definition)

- Profile

- Polarized

2. RESOLUTION: (your definition)

(literature definition)

- Quantum Effects, Digital Limits, Human eye limit (1minute of arc at 250mm, Abbe)

- $\mathrm{d}=\lambda / \mathrm{NA}$

3. MAGNIFICATION: (your definition)

(literature definition)

- Measure bars

- Eyepiece / Objective Calculations

4. DEPTH OF FIELD: (your definition)

(literature definition)

- $\mathrm{DF}=\lambda\left(\mathrm{n}^{2}-\mathrm{NA}\right)^{1 / 2} / 2 \mathrm{NA}^{2}$

- Wavelength

- Aperture

5. SURFACE TYPES: (your terms)

(literature terms)

- Features (inclusions, precipitates, grain boundaries)

- Anisotropic metals

- Etchants

TYPES OF OPTICAL MICROSCOPES: (your categories)

(literature terms)

- Lighting (BF, DF, P, $\lambda$ ), Interference

\section{MICROGRAPH FEATURES:}

- Grains, Boundaries, Shapes, Phases, Volume Fraction,

- Example structures: Ferrite, Pearlite, Cementite,

QUESTION: Find two example microstructures (one excellent and one poor), and critique them. Evaluate how effective each is, and suggest improvements. (10/99 Craig Johnson, CWU) 


\section{Appendix B - SPATIAL TERMS: (Instructor Guide)}

1. CONTRAST: (VV pg 285) "The ratio of the brightness of some specific detail to that of an adjacent structure or to that of the background."

- Profile

- Polarized

2. RESOLUTION: (pg 285) "Resolving power is the ability to produce separate images of multiple structures under the best conditions and is usually expressed as the number of uniformly spaced similar parallel black lines per unit length on a white background that can be separated in the image."

- $\mathrm{d}=\lambda / \mathrm{NA}$

- Quantum Effects, Digital Limitations

- Human eye limit of 1 minute of arc at $250 \mathrm{~mm}$ (Abbe)

3. MAGNIFICATION: (pg 280) "In the compound microscope, the image produced by the objective lens system is further magnified by the eyepiece. The total magnification is, therefore, the product of the magnification of the objective lens and the eyepiece"

- Measure bars

- Eyepiece / Objective Calculations

4. DEPTH OF FIELD: (pg 289) " The depth of field is the distance along the optical axis over which details of the object can be observed with adequate sharpness."

- $\mathrm{DF}=\lambda\left(\mathrm{n}^{2}-\mathrm{NA}\right)^{1 / 2} / 2 \mathrm{NA}^{2}$

- Wavelength

- Aperture

5. SURFACE TYPES: (pg 268) As-polished vs. relief polished, and etched vs. unetched.

- Features (inclusions, precipitates, grain boundaries)

- Anisotropic metals

- Etchants

TYPES OF OPTICAL MICROSCOPES: (pg 292)

- Lighting (BF: bright field: light comes down the optical path and reflects off spec)

- DF: Light originates at an incident angle external to the optical path.

- $\quad$ P: Polarized light is generated by a grating next to the source. (Anodize, isotropic)

- $\lambda$ : UV, Fluorescence, IR

- Interference: generates straight fringes on a flat specimen (two ray source).

MICROGRAPH FEATURES: (pg 435)

- Grains (ASTM E112), Shapes, Statistics, Phases, Volume Fraction (ASTM E562)

- Example structures: Ferrite, Pearlite, Cementite, 